\title{
Orocaecal transit time in Duchenne muscular dystrophy
}

\author{
Stanley H Korman, Benjamin Bar-Oz, Esther Granot, Shirley Meyer
}

\begin{abstract}
Smooth muscle degeneration may occur in Duchenne muscular dystrophy. We measured fasting orocaecal transit time in patients with advanced Duchenne muscular dystrophy and other muscular dystrophies and in healthy controls. No significant differences were found. In contrast to reports of gastric hypomotility in Duchenne muscular dystrophy, we found no evidence of impaired small intestinal motility.
\end{abstract}

Although the predominant manifestations of Duchenne muscular dystrophy relate to skeletal and cardiac muscle, gastrointestinal smooth muscle may also be involved. ${ }^{1-3}$ Severe and even fatal cases of acute gastric dilatation and intestinal pseudo-obstruction have been reported and associated with histological evidence of smooth muscle fibrosis throughout the gastrointestinal tract. ${ }^{1-3}$ To determine whether or not significant dysfunction of gastrointestinal motility occurs, we used the lactulose breath hydrogen test to measure orocaecal transit time ${ }^{4}$ in patients with advanced Duchenne muscular dystrophy and other neuromuscular disorders.

\section{Subjects and methods}

The lactulose breath hydrogen test was performed in three study groups. (1) This group comprised 10 patients with Duchenne muscular dystrophy who were confined to a wheelchair; their mean (SD) age was $17 \cdot 0(1 \cdot 8)$ years, range 15-20. (2) This group comprised 10 patients (seven boys) with other neuromuscular disorders (congenital muscular dystrophy $(n=3)$, limb girdle muscular dystrophy $(n=3)$, spinal muscular atrophy type II $(n=3)$, and hereditary motor and sensory neuropathy $(n=1))$; they were aged 14.5 (3.0) years, range 9-20. (3) This group comprised 10 healthy volunteer controls (six boys) who were aged $19.8(8.4)$ years, range 12-37. One patient with Duchenne muscular dystrophy and two with other neuromuscular disorders required regular enemas because of constipation. The others had no gastrointestinal symptoms. The study protocol was approved by the hospital ethics committee and informed consent was obtained from each subject and/or guardian. No subject had received antibiotics for two weeks or laxatives for three days before being studied.

After a 12 hour overnight fast each subject ingested $13.4 \mathrm{~g}$ of lactulose $(20 \mathrm{ml}$ of Duphalac, Duphar) made up to $200 \mathrm{ml}$ with water. Subjects blew into a collecting system with two bags that filled sequentially. The dead space air was trapped in the first bag; samples of end expiratory (alveolar) air were taken from the second bag for determination of hydrogen concentration using a Model 12 MicroLyzer (QuinTron Instrument Company) calibrated before each use with a standard gas. Samples were collected twice for baseline determination before lactulose administration and every 10 minutes thereafter for at least 120 minutes. Orocaecal transit time was defined as the time to a sustained rise of hydrogen concentration $\geqslant 10 \mathrm{ppm}$ above baseline.

\section{Results}

The lactulose breath hydrogen test was performed uneventfully in all subjects. A typical study is illustrated in fig 1. Breath hydrogen concentration rises when lactulose reaches the caecum where it is fermented by the colonic flora producing hydrogen, which is absorbed and excreted by the lungs. One subject in each of the three study groups exhibited an early transient hydrogen concentration peak preceding a later sustained rise (fig 1, lower graph). An early peak may result from fermentation of ingested carbohydrate by the oropharyngeal flora, ${ }^{5}$ or may be a sign of small bowel bacterial contamination. ${ }^{6}$ The magnitude of the early rises in these three subjects $(21,29$, and 32 ppm) is more suggestive of bacterial overgrowth, although none had any related symptoms.

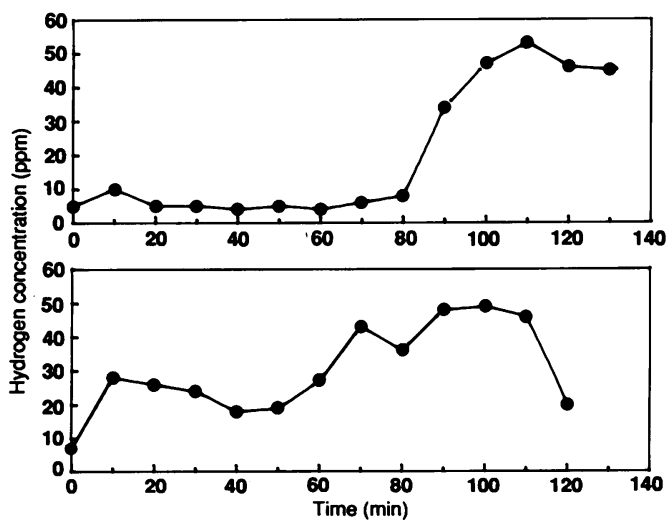

Figure 1 Upper graph: a typical lactulose breath hydrogen study in a 16 year old patient with Duchenne muscular study in a 16 year old patient with Duchenne muscular
dystrophy showing an orocaecal transit time of 90 minutes. Lower graph: lactulose breath hydrogen study in a 16 year old patient with Duchenne muscular dystrophy with an early peak at 10 minutes indicating bacterial overgrowth and a secondary rise at 70 minutes representing the orocaecal transit time. 


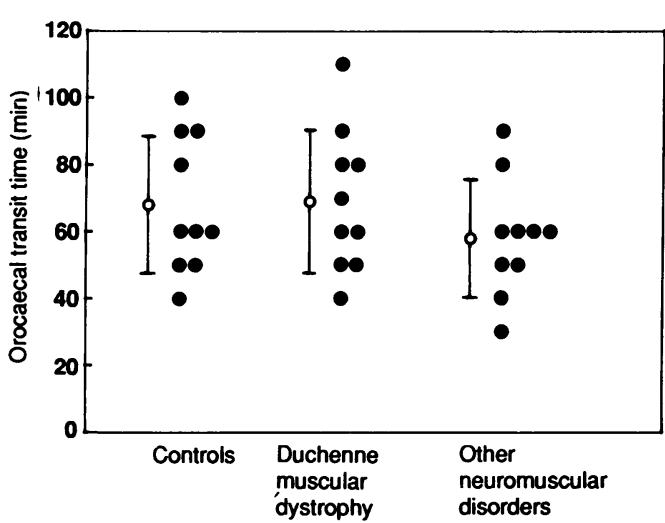

Figure 2 Orocaecal transit time in 10 control subjects, 10 Duchenne muscular dystrophy patients and 10 patients with other neuromuscular disorders. Vertical bars to left of each group indicate mean (SD) values.

Mean (SD) orocaecal transit time was $68 \cdot 0$ $(20 \cdot 4)$ minutes in controls, $69 \cdot 0(21 \cdot 3)$ minutes in the patients with Duchenne muscular dystrophy, and $58.0(17.5)$ minutes in the patients with other neuromuscular disorders (fig 2). There was no significant difference between the groups $(p=0.55$, Kruskal-Wallis test).

\section{Discussion}

Despite postmortem evidence of significant gastrointestinal smooth muscle degeneration in Duchenne muscular dystrophy, ${ }^{1-3}$ little attention has been paid to studying its functional consequences. Barohn et al recently documented gastric hypomotility in Duchenne muscular dystrophy patients and postulated that it may be related to a deficiency of dystrophin, the gene product of the Duchenne muscular dystrophy locus. ${ }^{3}$

We found no evidence of delayed fasting orocaecal transit time in either Duchenne muscular dystrophy or other neuromuscular disorders. Our results do not exclude the possibility of delayed gastric emptying in our patients. The orocaecal transit time as measured by the lactulose breath hydrogen test is dependent solely on small intestinal transit time and is not influenced by gastric emptying time. ${ }^{4}$ This is because orocaecal transit time is determined by the time taken for the head (rather than the bulk) of the lactulose column to reach the caecum. Even if gastric emptying is significantly delayed, a small amount of lactulose will still pass through the pylorus almost immediately after ingestion.

There is no uniformly accepted methodology for determination of orocaecal transit time using the lactulose breath hydrogen test. We measured it using a solution of lactulose in the fasting state only. This straightforward method has been successfully used to demonstrate the influence on intestinal transit of various states such as cystic fibrosis, ${ }^{8}$ thyroid disease, ${ }^{9}$ and aerobic exercise. ${ }^{10}$ Determination of postprandial oro- caecal transit time using standard liquid ${ }^{11}$ or solid $^{12}$ meals has been shown to improve the reproducibility of the test. We cannot exclude the possibility that subjects with Duchenne muscular dystrophy may have an abnormality in small intestinal motility detectable only in the postprandial state.

The apparent discrepancy between our finding of normal small intestinal motility in contrast to the gastric hypomotility in Duchenne muscular dystrophy described by Barohn et al is unlikely to be due to a difference in the patients studied $^{3}$; the mean age of both groups was almost identical, and all of our patients were confined to wheelchairs. A more likely explanation supported by histological findings from postmortem studies is that the degenerative process predominantly affects the upper gastrointestinal smooth muscle. ${ }^{3}$

Some patients with Duchenne muscular dystrophy suffer from constipation. Our findings suggest that the constipation is not due to impaired small intestinal motility. Colonic motility, another possible factor in the genesis of constipation, has not yet been studied in Duchenne muscular dystrophy. Most likely, however, the constipation in these patients is related to their immobility and weakness of their abdominal wall musculature.

Despite our finding of normal fasting small intestinal transit time, we cannot exclude the presence of small intestinal smooth muscle degeneration in our patients as such changes have been demonstrated at postmortem examination in the absence of overt clinical symptoms. ${ }^{1}$ We can, however, conclude that we have found no evidence for impairment of small intestinal motility even in advanced Duchenne muscular dystrophy.

1 Huvos AG, Pruzanski W. Smooth muscle involvement in primary muscle disease. II. Progressive muscular dystroprimary muscle disease. II. Progressive muscul
phy. Archives of Pathology 1967;83:234-40.

2 Nowak TV, Ionasescu V, Anuras S. Gastrointestinal manifestations of the muscular dystrophies. Gastroenterology 1982;82:800-10.

3 Barohn RJ, Levine EJ, Olson JO, Mendell JR. Gastric hypomotility in Duchenne's muscular dystrophy. $N$ Engl $\mathcal{f}$ Med 1988;319:15-8.

4 Bond JH, Levitt MD. Investigation of small bowel transit time in man utilizing pulmonary hydrogen $\left(\mathrm{H}_{2}\right)$ measurements. F Lab Clin Med 1975;85:546-55.

5 Thompson DG, O'Brien JD, Hardie JM. Influence of the oropharyngeal microflora on the measurement of exhaled breath hydrogen. Gastroenterology 1986;91:853-60.

6 Rhodes JM, Middleton P, Jewell DP. The lactulose hydrogen breath test as a diagnostic test for small-bowel bacterial overgrowth. Scand $\mathcal{f}$ Gastroenterol 1979;14:333-6.

7 Read NW, Cammack J, Edwards C, Holgate AM, Cann PA, Brown C. Is the transit time of a meal through the small intestine related to the rate at which it leaves the stomach? Gut 1982;23:824-8.

8 Bali A, Stableforth DE, Asquith P. Prolonged smallintestinal transit time in cystic fibrosis. $\mathrm{Br}$ Med $\mathcal{f}$ 1983;287:1011-3.

9 Shafer RB, Prentiss RA, Bond JH. Gastrointestinal transit in thyroid disease. Gastroenterology 1984;86:825-5.

10 Meshkinpour H, Kemp C, Fairshter R. Effect of aerobic exercise on mouth-to-cecum transit time. Gastroenterology

11 La Brooy SJ, Male P-J, Beavis AK, Misiewicz JJ. Assessment of the reproducibility of the lactulose $\mathrm{H}_{2}$ breath test as a measure of mouth to caecum transit time. Gut measure of mo

12 De Vries JJ, Collin T, Bijleveld CMA, Kleibeuker JH, Vonk RJ. The use of complex carbohydrates in barley groats for determination of the mouth-to-caecum transit time. Scand f Gastroenterol 1988;23:905-12. 